\title{
El Discurso Capitalista Neoliberal desde una perspectiva lacaniana*
}

HERNÁN FAIR**

Artículo recibido: 19 de abril de 2017

Artículo aprobado: 28 de junio de 2018

Doi: http://dx.doi.org/10.12804/revistas.urosario.edu.co/desafios/a.5586

Para citar este artículo: Fair, H. (2019). El Discurso Capitalista Neoliberal desde una perspectiva lacaniana. Desafíos, 31(1), 193-235. Doi: http://dx.doi.org/10.12804/revistas.urosario. edu.co/desafios/a.5586

Mediante el instrumento del lenguaje se instaura cierto número de relaciones estables, en las que puede ciertamente inscribirse algo mucho más amplio, algo que va mucho más lejos que las

enunciaciones efectivas.

El reverso del psicoanálisis

Jacques Lacan

\section{Resumen}

Este trabajo analiza el modo de construir subjetividad politica del capitalismo neoliberal desde herramientas de la teoria de los discursos de Jacques Lacan. Se concluye que durante los años noventa el neoliberalismo se constituyó como un nuevo Discurso Amo. El nuevo Amo se estructuró mediante una articulación aggiornada del Discurso Capitalista con el Discurso Universitario y una reformulación del Discurso del Amo Antiguo. A partir

\footnotetext{
* Este trabajo se inscribe dentro de mi tema actual de investigación en el CONICET y fue financiado de forma íntegra por dicho organismo.

** Doctor en Ciencias Sociales en la Universidad de Buenos Aires (UBA). Investigador adjunto del Consejo Nacional de Investigaciones Científicas y Técnicas (CONICET), con sede en el Centro IESAC de la Universidad Nacional de Quilmes (UNQUi). Profesor en la UNQUI. Correo electrónico: hernanfair@conicet.gov.ar ORCID: http://orcid. org/0000-0002-2082-8257
} 
de las construcciones metafóricas y los mandatos superyoicos de sus representantes y voceros, este discurso fue investido de un goce y un plus de goce lenguajero y corporal. A su vez, el Amo se mostró transfiriendo una parte del goce al Esclavo-Trabajador mediante una fantasía de libertad para elegir de forma plena y autónoma en el mercado, participar borizontalmente con el patrón en el nuevo orden flexible y acceder, vía el sacrificio, a un futuro de derrame de las riquezas de los ricos. Esta ilusión de retorno del goce al Esclavo fortaleció la dominación política del Amo-Empresario. En el caso argentino, junto con la permanencia de la Convertibilidad como objeto a causa de deseo, de Menem a De la Rúa (1989-2001) se encontró un cambio de registro en los mandatos superyoicos y en las fuentes de goce, dentro de un mismo Discurso Capitalista Neoliberal de disciplinamiento social. Palabras clave: teoría de los discursos, capitalismo neoliberal, goce, teoría política, psicoanálisis lacaniano.

\title{
The Neoliberal Capitalist Discourse from a Lacanian Perspective
}

\begin{abstract}
Thispaper analyzes the way to build political subjectivity of neoliberal capitalism using tools from Lacan's theory of discourses. I concludes that neo-liberalism was constituted as a new master discourse during the 1990s. The new master was structured through an updated articulation of the capitalist discourse with a university discourse and a reformulation of the old master discourse. Through the metaphorical constructions and the superego mandate of their representatives, this discourse was invested with a corporal and linguistic enjoyment. In turn, the master demonstrated giving up part of the enjoyment to the slave-worker through a fantasy of freedom in order to choose autonomously in the market, participate horizontally with the boss in the new flexible order and access, through sacrifice, a future of wealth of the rich. This illusion of the return of enjoyment to the slave reinforced the political domination of the master-businessman. In the Argentinean case, together with the Convertibility Plan as an object a cause of desire, from Menem to De la Rúa it was found a change of register in the superego commands and in the sources of enjoyment, within a same neoliberal capitalist discourse of social disciplination.
\end{abstract}

Keywords: Theory of discourses, neoliberal capitalism, enjoyment, political theory Lacanian psychoanalysis. 


\section{O Discurso Capitalista Neoliberal desde uma perspectiva lacaniana}

\section{Resumo}

Este artigo analisa o modo de construir subjetividade politica d capitalismo neoliberal desde ferramentas da Teoria dos Discursos de Jacques Lacan. Se conclui que durante os '90 o neoliberalismo se constituiu como um novo Discurso Amo. O novo Amo se estruturou mediante uma articulação aggiornada do Discurso Capitalista com o Discurso Universitário e uma reformulação do Discurso do Amo Antigo. A partir das construções metafóricas e os mandados superegóicos de seus representantes e porta-vozes, este discurso foi investido de um goze e um plus de linguageiro e corporal. Ao mesmo tempo, o Amo mostrou-se cedendo uma parte do goze ao Escravo-Trabalhador mediante uma fantasia de liberdade para escolher de forma plena e autônoma no mercado, participar horizontalmente com o patrão na nova ordem flexivel $e$ aceder, via o sacrifício, a um futuro de derrame das riquezas dos ricos. Esta ilusão de retorno do goze ao escravo reforçou a dominação política do Amo-Empresário. No caso argentino, junto com a permanência da Convertibilidade como objetivo, de Menem a De la Rúa se encontrou uma mudança de registro nos mandados superegóicos e nas fontes de goze, dentro de um mesmo Discurso Capitalista Neoliberal de disciplinamento social.

Palavras-chave: teoria dos discursos, capitalismo neoliberal, goze, teoria politica, psicanálise lacaniana.

\section{Introducción}

Este trabajo se propone analizar el modo de construir subjetividad política del capitalismo neoliberal desde una perspectiva de izquierda antiesencialista que se basa en herramientas de la teoría de los discursos de Jacques Lacan ¿De qué modo se estructuró políticamente el discurso neoliberal? En ese marco, ¿qué aportes específicos puede brindarnos las herramientas del Seminario 17 para el análisis sociopolítico y la crítica radical de este fenómeno? Para responder a estos interrogantes, el trabajo se estructura en dos partes. En la primera parte, a través de herramientas de la teoría de los discursos de Lacan 
y de algunas analogías con la teoría y la filosofía política, se construye una tipología de discursos. En la segunda parte, se analiza la estructuración hegemónica del discurso neoliberal a través de esta construcción conceptual. Por último, se pone en juego el artefacto teórico para examinar algunas particularidades del discurso neoliberal durante los gobiernos de Menem y De la Rúa en la Argentina (1989-2001).

\section{Consideraciones teóricas}

Sobre las herramientas de la teoría de los discursos de Lacan y sus usos desde el análisis sociopolítico y crítico

Este trabajo emplea algunas herramientas de la vertiente teórica lacaniana para el análisis político y social. Se enfoca en las contribuciones del Seminario 17. El reverso del psicoanálisis (Lacan, 2006). Se han destacado las vinculaciones que existen entre este Seminario y la teoría política contemporánea, en particular con la teoría posestructuralista del discurso y las identidades políticas de Ernesto Laclau ${ }^{1}$. Žižek (1992; 2005; 2006), Stavrakakis (1999; 2007) y Alemán (2009), además, aportaron valiosos recursos para el análisis sociopolítico y crítico a partir de categorías del Seminario 17, el primero desde la escuela lacaniana eslovena, y los otros dos desde una perspectiva que definieron como de "izquierda lacaniana".

En los últimos tiempos, las investigaciones que articulan aportes de la teoría psicoanalítica lacaniana y la teoría política se encuentran en boga, en particular desde la Teoría del Discurso de la Escuela de

\footnotetext{
1 Véase, por ejemplo, Fair (2010, pp. 127 y ss.). Sobre las afinidades más generales entre estas dos teorías, véanse Stavrakakis (1999; 2007) y Glynos \& Stavrakakis (2004).

2 Con independencia de las discusiones sobre la pertinencia de este significante para caracterizar a la teoría psicoanalítica (hay autores que consideran que el psicoanálisis es una teoría del sujeto y que no es ni de izquierda ni de derecha), sobre las ideas políticas de Lacan y sobre las múltiples interpretaciones en torno a su obra (que incluyen, además de las propuestas de Laclauy Žižek, a autores como Badiou, Castoriadis y Butler), se debe tener en cuenta que, desde un enfoque antiesencialista, los conceptos carecen de esencias y pueden ser usados como caja de herramientas más allá de las ideas políticas del autor, tal como lo hace el propio Lacan con Heidegger, Marx y Hegel.
} 
Essex. Sin embargo, en América Latina contamos con exiguos estudios políticos que, partiendo desde una perspectiva de izquierda posfundacional y posmarxista, articulen herramientas propias de la teoría de los discursos de Lacan y contribuciones lacanianas que examinaron los vínculos entre psicoanálisis y política (Alemán, Braunstein, Stavrakakis, Žižek, etc.), con el objeto de realizar un Análisis Político del Discurso (APD) neoliberal en la Argentina de los años noventa.

En el Seminario 17 (noviembre de 1969-junio de 1970) Lacan (2006) efectúa, a partir de una lectura de la fenomenología hegeliana de Alexander Kojève, una reinterpretación psicoanalítica y posestructuralista de la dialéctica del Amo y el Esclavo (sin una superación final de la dialéctica). Distingue cuatro discursos: Discurso del Amo, Discurso Universitario, Discurso de la Histérica y Discurso del Analista. Luego incorpora un quinto discurso, que define como Discurso Capitalista. Cada uno de estos discursos representa un modo de estructurar el lazo social (Lacan, 2006, p. 11). En efecto, "los discursos inducen identificaciones y de ellas están hechas las subjetividades y los lazos sociales" (De Santos, 2006, p. 27). En este sentido, Lacan asume que "la estructura de un discurso precipita el lazo social" (Mazzuca, 1992, p. 114). Como señala Gutiérrez Vera, debido a que para Lacan el discurso construye el lazo social, "es imposible concebir ningún nexo entre humanos que no presuponga el discurso"3 (Gutiérrez Vera, 2004, p. 316). Como indica Álvarez, la centralidad del discurso

\footnotetext{
3 Aunque no es motivo de análisis de este trabajo, Lacan afirma que el discurso se constituye a través de "cadenas significantes" (Lacan, 1987, p. 246; 2003 p. 24) que se articulan a ciertos significados para representar al sujeto (un sujeto que está "dividido" o "tachado" por efecto del orden significante: \$). Esta cadena significante se acolchona en torno a un "punto nodal" (Lacan, 1987, p. 160) que apunta al objeto pequeño a (objeto petit a). En el Seminario 17, Lacan señala que la cadena significante (a la que define como S2) encuentra como "punto de almohadillado" (Lacan, 2006, p. 205) a un "significante Amo", o S1, que articula la batería de significantes para "representar al sujeto" (Lacan, 2006, p. 93). Según Lacan, "S1 debe considerarse como el significante que interviene. Interviene sobre una batería significante que nunca, de ningún modo, tenemos derecho a considerar como dispersa, como si no formara ya la red de lo que llamamos un saber" (Lacan, 2006, p. 11). Sobre la teoría lacaniana del discurso, véase Álvarez (2006). Sobre sus diversos usos desde el análisis político y social, véanse Žižek (1992, especialmente pp. 125-146), Stavrakakis (1999, 2007) y Gutiérrez Vera (2004).
} 
como estructurador del lazo social constituye la principal innovación de la teoría lacaniana:

De la afirmación del psicoanálisis como práctica de discurso, el término principal es el de discurso, categoría que constituye la novedad lacaniana respecto de cómo ha venido planteando Freud la relación a otro en términos de lazos libidinales (Álvarez, 2006, p. 24).

A partir de una "torsión" de la obra freudiana (Rabinovich, 2008, p. 10), en el Seminario 17 Lacan incorpora "el plano de lo interdiscursivo" (Álvarez, 2006, pp. 16-17). Pero además, va más allá de Freud para "pensar modalidades de lo colectivo que no necesariamente sean las de la masa" (Álvarez, 2006, p. 102). Cada uno de los discursos constituyentes del lazo social representa "estructuras" que ocupan "distintas posiciones" y se escriben formalmente mediante matemas (Lacan, 2006, p. 45). Sin embargo, a través de la fenomenología de Kojève, Merleau-Ponty y Heidegger, Lacan analiza los giros históricos de estos discursos. Aunque parte de un planteamiento estructural, al mismo tiempo "habla del Amo antiguo y Amo moderno, el surgimiento de la ciencia, discurso capitalista, etc. Se trata de marcadores históricos" (Álvarez, 2006, p. 21). Además, "lo histórico, para el psicoanálisis, está incluido en la estructura, aun como agujero" (Álvarez, 2006, p. 17). De allí que desde Lacan se incluya a la "dimensión histórica" para comprender las condiciones del lazo social.

En el Seminario 17 el análisis de los discursos como estructuras que ocupan diferentes posiciones se pone a prueba mediante un abordaje histórico en torno a las variantes del lazo social desde la Antigüedad hasta la Modernidad tardía europea. Žižek refiere, en este sentido, a la "historicidad inscripta en la matriz lacaniana de los cuatro discursos". Esta incluye un análisis de la dominación del Amo desde la monarquía absoluta (Amo antiguo), hasta el imperio de los expertos y el mundo administrado del capitalismo (Discurso Universitario) y sus variantes "socavadoras", es decir, la "duda" racional que inicia Descartes (Discurso Histérico) y la "revolucionaria-emancipadora" (Discurso del Analista) (Žižek, 2005). La historicidad de la teoría 
lacaniana de los discursos también presupone que "un mismo sujeto puede operar en distintas posiciones dentro de una misma estructura discursiva, o en discursos diferentes" (Gutiérrez Vera, 2004, s/p). Esto permite pensar en mutaciones históricas y también en combinaciones de las posiciones de sujeto.

La otra novedad de este Seminario es la vinculación de los discursos con un modo particular de administrar el goce (Álvarez, 2006, p. 15). El goce constituye un concepto lacaniano que se vincula con el placer que "cede al displacer". Concierne, básicamente, al cumplimiento de ciertos mandatos imperativos del superyó (igoza!) que se encuentran investidos libidinalmente, más allá del principio del placer (Žižek, 1992, p. 118; Braunstein, 2006). Lacan lo relaciona con "el predominio de la mujer como madre, y madre que dice, madre a quien se pide, madre que ordena y así instituye la dependencia del niño" (Lacan, 2006, p. 82). A diferencia de Freud, desde la perspectiva de Lacan el goce se vincula directamente con "la función del surgimiento del significante" (Lacan, 2006, p. 17). Esto supone que "el significante se introduce como aparato de goce" (Lacan, 2006, p. 51). Sin embargo, debido a que la "castración" (fálica) que instaura el orden simbólico implica la "pérdida del goce sexual" con la Cosa (el cuerpo de la madre), la recuperación del goce desde el orden significante siempre representa "cierta pérdida" parael sujeto (Lacan, 2006, p. 17).

Lacan, además, afirma que "hay una relación primaria del saber con el goce” (Lacan, 2006, p. 17) y una relación estrecha entre el saber, el goce y la dominación política. En ese marco, plantea "la cuestión del lugar que tiene el psicoanálisis en lo político". Y sostiene que "solo es posible entrometerse en lo político si se reconoce que no hay discurso, y no solo analítico, que no sea del goce"4 (Lacan, 2006, p. 83). Como señala Laurent:

El referente de cualquiera de estos discursos es entonces un modo de tratar el goce: sea el modo del Amo, sea el modo Universitario, sea en la Histérica, sea en el discurso del Analista (Laurent, 1992, p. 31).

4 Sobre la noción de goce en Lacan, véanse Braunstein (2006) y Rabinovich (2008). Sobre los vínculos entre el goce y el análisis político, véanse Žižek (1992; 2006) y Stavrakakis (1999; 2007). 
En este Seminario, sin embargo, Lacan va más allá de la lingüística y se refiere a la posibilidad de que exista un discurso "sin palabras" que instaura "ciertas relaciones fundamentales", aunque estas relaciones sociales "no pueden mantenerse sin el lenguaje" (Lacan, 2006, p. 10). A partir de allí, autores como Žižek (1992) y Braunstein (2006, pp. 90 y ss.) distinguen analíticamente, desde la enseñanza de Lacan, entre dos tipos de goce. Por un lado, un goce lenguajero o "fálico", que se constituye a partir de metáforas y metonimias verbales. Por el otro, un goce corporal o goce "en el cuerpo", producto de las prácticas sociales de los sujetos que actúan como una pantalla de la fantasía imaginaria que estructura la realidad simbólica. Ambos modos de goce solo adquieren significación a través del orden significante.

Finalmente, en el Seminario 17 Lacan realiza una crítica teórica y epistemológica a los discursos Amo, con el objeto de "subvertir" su dominación (Lacan, 2006, p. 84). Por un lado, esta crítica pone "en el banquillo al saber", entendido como "totalidad" (Lacan, 2006, p. 31). Vinculando al saber con el poder, Lacan sostiene que "la referencia a un discurso es lo que manifiesta querer dominar". Aunque a continuación aclara que "el discurso del analista debe encontrarse en el punto opuesto a toda voluntad, al menos manifiesta, de dominar" (Lacan, 2006, p. 73). Y por otro lado, cuestiona al Discurso Capitalista al mostrar su estructuración como nuevo Amo y el goce adherido a su enunciación y a sus prácticas materializadas de forma corporal. En este punto, Lacan critica la creación del Discurso Capitalista de objetos petit a de consumo mercantil que se construyen desde el orden significante como si fueran necesidades para el sujeto ${ }^{6}$. Al mismo tiempo, asocia el concepto de plusvalía de Marx con la noción de "plus de

\footnotetext{
5 Como afirma Gutiérrez Vera, "Puede haber discurso aun cuando ninguna palabra haya sido pronunciada (el discurso no es el habla), porque el discurso apunta a las relaciones invariantes (de estructura) que el lenguaje establece entre sujetos" (Gutiérrez Vera, 2004, p. 317).

6 "En cuanto a los pequeños objetos a minúscula que se encontrarán al salir, ahí, sobre el asfalto en cada rincón de la calle, tras los cristales de cada escaparate, esa profusión de objetos hechos para causar su deseo, en la medida en que ahora es la ciencia quien la gobierna, piénsenlos como letosas" (Lacan, 2006, p. 174). Lacan advierte, además, que "Se haga lo que se haga, se diga lo que se diga, como tratar de unir esta producción de necesidades que son necesidades que se crean, no hay nada que hacer" (Lacan, 2006, p. 188).
} 
goce". Y afirma que la sociedad de consumo promueve la proliferación de objetos mercantiles ( que define como "letosas") investidos de un plus de goce 7 . En contraste con estos discursos Amo, Lacan se identifica con la posición "no toda" del analista (Lacan, 2006).

Teniendo en cuenta las profundas convergencias entre la vertiente psicoanalítica lacaniana y la teoría política posfundacional, que incluso permiten situar a Lacan como un antecedente del posmarxismo, consideramos que resulta fundamental fortalecer estos dialogismos a nivel teórico y sociopolítico.

\section{Breves consideraciones sobre el neoliberalismo}

El neoliberalismo o nuevo liberalismo económico representa un concepto polisémico y ha sido analizado por la bibliografía especializada desde diferentes enfoques y perspectivas (Dornbusch \& Edwards, 1990; García Delgado, 1994; Torre, 1998; Anderson, 1999; Bourdieu, 1999; Borón, 2000; Brenner \& Theodore, 2002; Thwaites Rey, 2003; Ffrench Davis, 2004; Brown, 2006; Foucault, 2007; Harvey, 2007; Sassen, 2007; Morresi, 2007; 2008; Hall, 2011; Crouch, 2012; Gill, 2015, entre otras/os) ${ }^{8}$.

En este trabajo sostenemos que el neoliberalismo constituye al mismo tiempo un conjunto de ideas-fuerza que condensan un modelo o patrón de acumulación capitalista y un proyecto ético-político, una concepción del mundo y una ideología (que incluye un lenguaje político asociado a ciertas creencias, valores y prácticas discursivas de carácter mítico, fantasioso e imaginario) que privilegia, como efecto del orden significante, los intereses, valores y deseos particulares del capital concentrado, genera precarización laboral, fragmentación social, pérdida de solidaridad entre los trabajadores y una exclusión social de las mayorías populares. Esta

\footnotetext{
En palabras de Lacan: "El sentido que tiene la sociedad de consumidores proviene de esto, que es a lo que constituye su elemento calificado, entre comillas, como humano, se le atribuye el equivalente homogéneo de cualquier plus de goce producto de nuestra industria" (Lacan, 2006, pp. 85-86).

8 No podemos extendernos sobre este tema. Para una síntesis de las discusiones en torno a este fenómeno, véase Peck \&Tickell (2002, pp. 381-383).
} 
ideología fantasmática tuvo en las últimas décadas un considerable éxito para trascender sus intereses "corporativos" (Gramsci, 1984), generar un cierre ilusorio de la sociedad (Laclau, 2014) y construir un sedimentado sentido común entre sus principales víctimas, es decir, los TrabajadoresEsclavos que forman parte de los grupos subalternos (en un sentido amplio en el que incluimos a trabajadores asalariados, desocupados, cuentapropistas/autónomos, jubilados y pensionados ${ }^{9}$ ).

El neoliberalismo presentó, a nivel estatal, diferentes etapas históricas que, a su vez, tuvieron diferentes características y grados de radicalización. En el presente trabajo nos centraremos en los cambios de los años noventa. En esta etapa el neoliberalismo logró conformar en gran parte de América Latina una nueva hegemonía, en el sentido que le otorga Laclau $(1985$, p. 30; 1996) de una exitosa capacidad de universalizar simbólicamente ciertos significados (valores, demandas, intereses) particulares para edificar un orden y un nuevo sentido común. El texto incluirá algunos aportes para analizar, desde una perspectiva lacaniana, el modo de construcción de la hegemonía neoliberal durante los gobiernos de Menem y De la Rúa. Se tiene en cuenta que el caso

9 En el Seminario 17, Lacan afirma que "Lo que el psicoanálisis nos permite concebir es ni más ni menos esto, que está en la vía inaugurada por el marxismo, a saber, que el discurso está vinculado con los intereses del sujeto. Es lo que Marx llama, en este caso, economía, porque en la sociedad capitalista esos intereses son enteramente mercantiles". Sin embargo, para Lacan, los intereses económicos son efectos del orden significante. De allí que, a continuación, agregue: "Pero como la mercancía está vinculada con el significante Amo, denunciarlo de este modo no resuelve nada. Porque después de la revolución socialista la mercancía no deja de estar vinculada con este significante" (Lacan, 2006, pp. 96-97). Desde estas premisas, Lacan realiza una crítica a La riqueza de las naciones, de Adam Smith, en la que asocia al Amo con el "rico" y luego lo vincula al "hombre de negocios" que usa el "plus de goce" del saber como un "aparato de explotación" del esclavo (Lacan, pp. 87-88). Tomando como base esta redefinición "posmarxista" de la dialéctica del Amo y el Esclavo, en este trabajo situamos a los grandes empresarios que, como dueños de los medios de producción, ocupan en la estructura social la posición dominante de capitalistas (incluyendo en un sentido amplio del término a terratenientes y a gerentes) como principales exponentes del DiscursoAmo Capitalista y a los sujetos que usan el supuesto saber en solidaridad con el Amo como sus voceros y representantes políticos. Al mismo tiempo, posicionamos a los trabajadores que no son dueños de los medios de producción y ocupan una posición subordinada en la estructura social (en un sentido amplio que incluye a los trabajadores asalariados manuales e intelectuales, los que se encuentran desocupados o subocupados, los que trabajan de forma no registrada, los cuentapropistas y autónomos y los que se jubilaron o cobran pensiones) como exponentes del Esclavo. 
argentino entre 1989 y 2001 constituye un ejemplo paradigmático del “experimento neoliberal" (Thwaites Rey, 2003), tanto por su "profundidad" como por su "intensidad" (Schorr, 2002, p. 12).

\section{La teoría de los discursos de Jacques Lacan}

En el Seminario 17 Lacan (2006) describe la existencia de "cuatro posiciones" que definen "cuatro discursos básicos" (Lacan, 2006, p. 18). Estos discursos constituyen diferentes modos de "estructurar" el lazo social. En primer lugar, Lacan se refiere al "Discurso del Amo" antiguo, que corresponde a la forma de dominación social propia de la Antigüedad y remite a la dialéctica del Amo y el Esclavo de Hegel. Desde la interpretación lacaniana, la figura del Amo condensa en sí mismo al significante Amo (el S1), quien solo desea que "la cosa funcione".Mientras que el esclavo representa a la cadena significante (S2) que posee el "saber hacer" (similar a un "saber artesanal"). Esta forma de estructurar el lazo social se condensa en la función enunciativa del Amo, quien "reconoce" al Esclavo y este se siente "reconocido" por el Otro (el Amo). De este modo, el Esclavo se identifica con su función de autoridad y obedece a sus mandatos (Lacan, 2006, pp. 19-22; Álvarez, 2006, pp. 92-93). Recordemos que, según Lacan, el deseo del hombre, mediado por el lenguaje, es "ser reconocido por el otro" (Rabinovich, 2003, 102 y ss.; 2008, p. 14). En este sentido, el reconocimiento del Amo permite "encarar la comprensión del amor que por los amos sienten los súbditos, del goce de su condición que nutre a los sometidos" (De Santos, 2006, p. 26).

El segundo discurso, que caracteriza a la Modernidad, es el Discurso Universitario (Lacan, 2006, pp. 31-32 y ss.), por momentos definido como el "Discurso de la Ciencia" (Lacan, 2006, p. 95). Este "giro" en el discurso produce "un cambio en el lugar del saber" (Álvarez, 2006, p. 94). Lo central del Discurso Universitario es la "desposesión del saber del esclavo", del que se apropia el nuevo Amo (Lacan, 2006, p. 94). En la Modernidad capitalista el nuevo amo comienza a utilizar el saber como una fuente de poder. El saber-poder se trasmuta en "verdad" objetiva y universal para justificar la sumisión del Esclavo. De allí que, con el nuevo 
Amo, la dominación no se centre en su figura como S1, sino en la forma de un "todo saber" como S2. La cadena significante se condensa en los mandatos superyoicos de un "sujeto supuesto saber" que se apropia y comanda el goce del Esclavo mediante un carácter anónimo (Álvarez, 2006, pp. 96-99). De manera tal que la Modernidad opera un desplazamiento del Amo antiguo desde su figura (S1) como "mito ultrarreducido, idéntico como es a su propio significante", hacia la "matemática" como S2 que representa el "saber del Amo" como "ciencia" (Lacan, 2006, p. 94). Esto marca el predominio de lo que De Santos (2006, p. 182) define como un "patrón que no tiene rostro".

La preponderancia de este discurso se comprende en el marco de los avances tecnocientíficos que caracterizan a la Modernidad capitalista desde los siglos XV y XVI. Lacan menciona la influencia de la ciencia física, la lógica proposicional aristotélica, la geometría euclidiana, el cálculo infinitesimal de Arquímedes y la filosofía matemática de Leibniz como precondiciones para referirse al "giro" en el modo de estructuración del discurso del "Amo antiguo" (Lacan, 2006, pp. 85, 94-96 y ss.). Este giro se expresa en la metamorfosis desde un tipo de dominación con base en la autoridad subjetiva de la enunciación, hacia el dominio político del "Amo moderno" que basa su dominación en el (supuesto) saber objetivo de la ciencia formal (Lacan, 2006, pp. 167-171). Como señala Lebrun (2003), con la Modernidad comenzó a predominar un discurso centrado en la autoridad de los enunciados objetivos, especialmente los lógico-matemáticos. Lacan vincula a este discurso Amo con la psicología conductista ya que se basa en una hipermedicalización del paciente y en un tipo de análisis objetivista que reniega de los factores deseantes e inconscientes del sujeto (Lacan, 2006, pp. 66, 77). Sin embargo, como se trata de una misma estructura de construcción del lazo social, realiza algunas analogías entre este discurso del "todo saber" y el socialismo real. Ello lo conduce a criticar la maquinaria de la "burocratización" objetivante de la Unión Soviética y a denunciar su intento de crear un nuevo Amo basado en el discurso Universitario (Lacan, 2006, pp. 32, 221). A su vez, ubica en esta misma posición a Adam Smith y a los "economistas" por crear teorías (como La riqueza de las naciones) que se encuentran al servicio de la dominación velada del Amo moderno (el "hombre de negocios") (Lacan, 2006, pp. 86-88). 
A partir de un "cuarto de vuelta", Lacan identifica un tercer discurso, al que define como el "Discurso de la Histérica". Lo vincula a la construcción de un sujeto (con independencia del género anatómico) dividido o tachado por efecto del orden significante (\$), que se dirige a un Amo, orientado por el deseo inconsciente de saber. Este discurso se basa en una lógica gozosa de mantener el "deseo insatisfecho" del Otro de forma permanente. De este modo expresa, de un modo sintomático, la imposibilidad de toda universalidad plena. Lacan reconoce la potencialidad de este discurso en posición de mujer para mostrar el carácter "no todo" del sistema que se pretende universalista y objetivista y "desenmascarar" la dominación del Amo. Afirma, además, que ello lo asemeja a la experiencia psicoanalítica (Lacan, 2006, pp. 34-35 y ss.). Sin embargo, el sujeto histérico "instala al padre en posición de Amo" (Laurent, 1992, p. 35). En este sentido, Lacan sostiene que, pese a "desenmascararlo", al mostrar que está "castrado", esta posición se mantiene "solidaria con la función del Amo" (Lacan, 2006, p. 99).

El "Discurso del Analista" representa aquella posición de sujeto que critica las fallas constitutivas del "supuesto saber" de la Ciencia, entendido como un "fantasma del saber totalidad". Como señala Lacan, "la experiencia psicoanalítica pone en el centro, en el banquillo, al saber". Y lo hace "luchando" contra la idea, habitual en política, de que "el saber pueda constituir una totalidad cerrada" (Lacan, 2006, p. 31). En ese marco, el Discurso del Analista realiza una "histerización” del Discurso de la Ciencia (Lacan, 2006, p. 33). Ello implica aceptar que lo social se encuentra construido por el orden simbólico y que está atravesado por el inconsciente (y, por lo tanto, por la alteridad y el hueso de lo Real), por lo que no puede alcanzarse ni la objetividad, ni la universalidad, ni la complementariedad social, ni la plena felicidad. De esta manera, el Discurso del Analistase basa en un acto de "subversión", que muestra el "fracaso" del saber como totalidad (Lacan, 2006, pp. 33-36 y ss.).

Sin embargo, Lacan distingue entre la posición del Analista y la de la Histérica. El Discurso de la Histérica, aunque lo desenmascara, es funcional a la dominación del Amo. En palabras de Lacan, "lo que 
la histérica quiere es un Amo"10 (Lacan, 2006, p. 137). El Discurso del Analista sostiene que el saber total y absoluto es "imposible", que constituye un fantasma (fantasía) (Lacan, 2006, p. 33). Aunque al mismo tiempo se opone al Amo. En este sentido, "el discurso del Amo solo tiene un contrapunto, el discurso analítico" (Lacan, 2006, p. 91). Pero esta posición discursiva no abandona las amarras con el Discurso Universitario y con la idea de Verdad. Luego de cuestionar la "posición psicótica", que se caracteriza por "no querer saber nada de ese rincón de donde se trata la verdad" (Lacan, 2006, p. 67) y de advertir que "la verdad es inseparable de los efectos del lenguaje" —lo que implica "incluir en ellos al inconsciente" —, Lacan sostiene que el Discurso del Analista funciona en "el registro de la verdad" (Lacan, 2006, p.145). Sin embargo, se caracteriza por enunciar la "verdad" desde un "medio decir", en tanto la verdad solo puede ser "mediodicha" (Lacan, 2006, pp. 36-37 y 115-116; 1971-1972, p. 4; 2008, p. 145; 2009, p. 12; 2012, p. 31). Ello implica defender un tipo de objetividad precaria y relativa que, en oposición al universalismo de la lógica proposicional aristotélica, asume a la verdad como "no toda". De esta manera, pese a que el analista es situado por el analizante en posición de sujeto supuesto saber, el Discurso del Analista debe cuestionar la "transferencia" pura del goce desde el saber hacia su figura. A su vez, debe rechazar la propia posición de dominio para situarse en un saber-verdad "barrado". Este saber no-todo se propone "ayudar" al paciente a reflexionar sobre su inconsciente, a partir de la función de la “interpretación” (Lacan, 2006, p. 92; Álvarez, 2006, p. 118).

Esta conceptualización del Discurso del Analista le permite a Lacan criticar las formas de dominación social que se basan en la objetividad científica del saber (Discurso Universitario) y en el intento de ocupar la posición de dominio del Amo antiguo (el Padre-líder) que asume

\footnotetext{
10 Las críticas al Discurso de la Histérica se entienden mejor en el contexto político en el que se dicta el Seminario 17, signado por las recientes movilizaciones del Mayo francés. Lacan (2006) cuestiona a los estudiantes que critican las fuentes de autoridad de los padres, maestros y políticos por buscar (inconscientemente) un nuevo Amo que los domine. De esta manera, se convierten en "ilotas" (esclavos) funcionales al régimen que critican (Lacan, 2006, p. 223). Como señala Žižek, Lacan asocia aquí a los estudiantes con una "reacción histérica" que es solidaria con el Amo (Žižek, 1992, p. 155).
} 
Freud $^{11}$ (Lacan, 2006, pp. 35-36 y ss.). En contraste con la posición conservadora de Freud y su pretensión de salvar a la figura del Padre omnipotente, para Lacan se trata de mostrar la falla constitutiva que atraviesa a todas las variantes del Amo. Luego, se busca recuperar el saber autónomo del sujeto (esclavo), forcluido a través de la presunta objetividad de la ciencia y de la apropiación del goce del Esclavo en manos del Amo moderno (Lacan, 2006, pp. 157-160). A partir de esta subversión del Amo, propia de la posición del analista, Lacan destaca la necesidad de estructurar nuevos lazos sociales, estructurados de una forma "no-toda" (Lacan, 2006, p. 112). En este sentido, como señala Álvarez, el Discurso del Analista supone una "responsabilidad ética" que "no se agota en un discurso de denuncia, en un pensamiento crítico, sino que nos propone una nueva apuesta". Una "política del síntoma", que permite incorporar "una respuesta que ponga en función a la falta” (Álvarez, 2006, pp. 224 y ss.).

Por último, sobre el final del Seminario, Lacan escribe en su pizarra un quinto discurso, al que denomina "Discurso Capitalista". Este discurso se caracteriza por incentivar el consumo de objetos mercantiles ("letosas" o "gadgets") creados por la llamada "Sociedad de consumo" para “causar su deseo" de ser consumidos (Lacan, 2006, pp 33, 174). $\mathrm{Al}$ ser construidos como "necesidades" para el sujeto-Esclavo, su falta o el peligro de su ausencia se traducen en una sensación de "angustia" (Lacan, 2006, pp. 175, 188). No obstante, a diferencia de la crítica de Marx (2007) al fetichismo de la mercancia, Lacan hace hincapié en las formas de dominación social del capitalismo con base en el saber y en los factores inconscientes, ligados al goce. Sostiene que el Discurso Capitalista genera un cambio de registro en la forma del saber que

\footnotetext{
11 Lacan critica el conservadurismo político y el cientificismo darwiniano de Freud. Lo acusa de pretender retornar al discurso de la ciencia y "preservar" la dominación del Padre (líder) a través de la creación del complejo de Edipo y el mito del padre de la horda primitiva que goza de todas las mujeres (Lacan, 1971-1972, p. 24; 2005; 2006, pp. 92 y ss.; 2008, p. 132). Sin embargo, la crítica al "padre omnipotente" no lo conduce a asumir una tesis anarquista de destitución paterna, sino a aceptar que el padre está estructuralmente "castrado" por efecto del orden significante y que la madre adquiere una importancia central en la identificación del sujeto (Lacan, 2006, especialmente pp. 126-138). Sobre las críticas de Lacan a Freud, véase Laurent (1992).
} 
caracterizaba a la Antigüedad. Este giro realiza una "sustracción" al trabajador-obrero-esclavo, pero no solo de la plusvalía (en el sentido marxista), sino del "plus de goce" que, inicialmente, se hallaba en manos del Esclavo y ahora pasa a estar en poder del nuevo Amo (Lacan, 2006, pp. 18, 85-86 y 113).

Lacan destaca la estrecha relación que existe entre la dominación capitalista y su administración de las fuentes de goce. El goce se vincula al cumplimiento (por la vía del discurso) de los mandatos superyoicos promovidos por la "tiranía del saber". Ello conduce al Esclavo a desear inconscientemente y a identificarse con el Amo y, por lo tanto, a asumir como propios sus mandatos, ligados al desarrollo tecnocientífico. Estos imperativos capitalistas incentivan al sujeto-esclavo a gozar de las pautas culturales de la sociedad de consumo y a creer en su promesa imaginaria de plenitud. Se constituye, así, una dialéctica circular del deseo que, a través de las prácticas de consumo pulsional de mercancías, es funcional a la perpetuación del capitalismo (Lacan, 2006, pp. 32 y ss.). El problema es que el Discurso Capitalista es un discurso "sin envés" (Alemán, 1992, p. 22). De allí que genere una "forclusión de la castración" que, al rechazar lo simbólico y negar el resto de lo Real, "hace imposible el amor en el mundo actual" (Álvarez, 2006, p. 191). Precisamente, la forclusión en el campo de lo social se materializa como una "imposibilidad del lazo" (Álvarez, 2006, p. 193). Y ello supone que ya "no hay eficacia de la función paterna” (Álvarez, 2006, p. 195).

\section{La potencialidad de la teoría de los discursos de Lacan para la teoría política y el análisis sociopolítico y crítico. Hacia la construcción de una tipología}

La teoría de los discursos de Lacan contiene valiosas contribuciones para la teoría política, el análisis sociopolítico y la crítica radicalizada. A partir de sus herramientas conceptuales, articuladas con algunas analogías de la teoría y la filosofía política, se plantea a continuación una tipología de discursos. Estos discursos constituyen diferentes modalidades de construcción del lazo social. 
1) Discurso patriarcalista-autoritario: corresponde a una reformulación contemporánea del discurso del Amo Antiguo que se basa en la imposición del poder arbitrario y coercitivo de la autoridad del líder-Padre. Este discurso Amo presenta una primacía de la autoridad subjetiva y personalista. Fundamenta la legitimidad de su dominación política en la enunciación de una figura paternalista como encarnación unaria del significante Amo (S1) y en su función simbólica castradora, que se vincula al lazo seguridad-paz/obediencia disciplinada. En una analogía con la teoría política moderna, se lo puede identificar con un discurso de matriz hobbesiana. Un ejemplo ilustrativo es la frase "El Estado soy yo", del monarca absoluto Luis XIV. Un ejemplo más reciente son las dictaduras militares en el Cono Sur de los años setenta (aunque desde la dinámica política existen grados e intensidades diferenciales de estructuración de este discurso del Amo).

2) Discurso tecnocrático: corresponde a una reformulación contemporánea del Discurso Universitario, que se basa en el (supuesto) saber superior (racional y objetivo) de la Ciencia económica y el conocimiento lógico-matemático para manejar la técnica de la gestión social. Este discurso Amo presenta una primacía de la autoridad objetivista de los enunciados científicos. Fundamenta la legitimidad de su dominación política en una cadena de significantes (S2) que se vincula al (supuesto) conocimiento experto $=$ objetivo $=$ neutral $=$ científico $=$ verdadero $=$ puramente técnico, administrativo o gestionario de lo social. El (presunto) saber superior es la fuente de estructuración del lazo social. Una analogía de este discurso se la puede encontrar a nivel epistemológico en Euclides, Parménides y la lógica formal de Aristóteles y, a nivel filosófico-político, en el discurso del filósofo-rey de Platón. Desde la teoría y la filosofía política moderna, las analogías se pueden establecer con el administrativismo tecnocrático de Saint-Simon, el empirismo de Bacon, Hume y Leibniz y el positivismo lógico de Carnap, Hempel, Schlink y Neurath. Además, encuentra vinculaciones con la economía positiva de Menger, Marshall, Walras, Pareto, Say, Pigou y las teorías conductistas de la psicología científica (Watson, Skinner), la ciencia política anglosajona (Apter, Merrian, Lowell, Bentley), la sociología funcionalista (Parsons, Merton) y el derecho (Kelsen). Como ejemplo histórico-político reciente se puede 
pensar en el discurso de los economistas de las fundaciones ortodoxas FIEL o CEMA en Argentina, o en los llamados Chicago Boys, quienes asesoraron a la dictadura militar de Pinochet en Chile.

3) Discurso posmoderno: corresponde a una reformulación contemporánea del Discurso de la Histérica que se basa en "histerizar" el orden social, al relativizar sus fundamentos epistemológicos y mostrar su propia imposibilidad (el "no-todo" del sistema). Este discurso presenta una primacía de los elementos subjetivos. Fundamenta su legitimidad en el acceso a un imaginario de libertades individuales ilimitadas y en la difusión de los múltiples particularismos. Se caracteriza por criticar y rechazar todo universalismo y objetivismo y, en ocasiones, toda fuente atributiva de autoridad. Ello implica construir un lazo social histérico que se enfoca en la crítica a las fallas del Amo como totalidad. Analogías de este discurso con la teoría y la filosofía política se pueden encontrar en Heráclito, en la "antifilosofía" nihilista de Nietzsche y en pensadores posmodernos como Lyotard y la teoría rizomática de Deleuze y Guattari. Como ejemplo histórico-político reciente se puede pensar en las movilizaciones sociales del 19 y el 20 de diciembre de 2001 en la Argentina y en su frase "iQue se vayan todos, que no quede ni uno solo!" (los políticos).

4) Discurso Capitalista: corresponde al tipo de dominación social, propia del orden capitalista, que se basa en la difusión de mandatos superyoicos de acumulación ilimitada de capital y en la creación discursiva de necesidades de consumo de mercancías fetichistas como presuntas fuentes de plenitud para los sujetos y carentes de resto. Fundamenta la legitimidad de su dominación política en la naturalización de la apropiación de plusvalía y del plus de goce del Amoempresario-capitalista sobre el trabajador-Esclavo, en la creación de necesidades de consumo mercantil de objetos a causa de deseo y en una fantasía de supresión de la falta constitutiva y la alteridad. Su justificación teórico-política se la puede encontrar en Adam Smith, David Ricardo, Locke, Bentham y en los economistas neoclásicos tempranos. Los antecedentes de su análisis crítico pueden hallarse en el estudio de Marx sobre El capital, en sus Manuscritos y en la Teoría Crítica de Adorno, Horkheimer y Marcuse. 
5) Discurso del Analista: corresponde al discurso que expone los límites y las fallas constitutivas y muestra los aspectos imaginarios y precarios (el "no-todo") del Amo y de todo ordenamiento social. Este discurso critica a los fundamentalismos y subvierte sus fuentes de dominación y opresión social sobre el Esclavo. Ello incluye a los discursos capitalistas, patriarcales, tecnocráticos y burocráticos, en cualquiera de sus formas y variantes histórico-políticas. Se caracteriza por exhibir el carácter inherentemente "tachado" (contingente, precario, relativo y parcial) de lo social desde una posición radicalmente crítica. Aunque, al mismo tiempo, construye nuevos lazos sociales a través de objetos parciales que edifican hegemonías emancipatorias precarias que se basan en el reconocimiento del saber popular y en la valoración de los conflictos, diferencias y particularidades como constitutivas y deseables ${ }^{12}$. Encuentra antecedentes teóricos en la docta ignorancia de Sócrates y en los escépticos, en la epistemología crítica de Godel, en el Wittgenstein tardío, en Quine y Frege, y algunos antecedentes políticos en Marx. Se pueden establecer analogías desde la teoría política contemporánea con la perspectiva posmarxista de la "democracia radical y plural" de Laclau y Mouffe. También con las concepciones de Žižek y Badiou.

Desde la dinámica política estos discursos pueden presentarse de forma combinada y asumir formas híbridas. Recordemos que el propio Lacan destaca, en el Seminario 17, que el "discurso del capitalista" realiza una "copulación con la ciencia” (Lacan, 2006, p. 116). También pueden presentarse giros y desplazamientos históricos en las posiciones ${ }^{13}$. Finalmente, estas posiciones discursivas pueden asumir, fenoménicamente, diferentes grados relativos de estructuración.

\footnotetext{
12 En este punto retomamos la interpretación de Stavrakakis (2007), para quien existe en Lacan una ética de la construcción del lazo social "parcial", que le permite distinguirse del discurso histérico.

13 Lacan rescata las contribuciones de la dialéctica de Hegel y sostiene que Marx fue el inventor del síntoma, aunque luego cuestiona sus derivaciones en un nuevo Discurso Universitario. Además, vincula al marxismo (vía el estalinismo) con el discurso del Amo moderno, y a Hegel con el intento de fundar la síntesis definitiva en el "saber absoluto" (Lacan, 2006, pp. 18, 31-32, 83; 2008, p. 129).
} 


\section{Las herramientas de la teoría de los discursos para analizar las formas de dominación del capitalismo neoliberal}

Durante los años noventa, la crisis de acumulación y de legitimación del régimen fordista-keynesiano, el derrumbe del bloque soviético, el fin de la Guerra Fría y la revolución tecnológica y de las telecomunicaciones, se tradujeron en un avance de las ideas liberal-democráticas, en la expansión de los medios masivos de comunicación y en una creciente interconexión comercial y financiera a escala mundial. Estas transformaciones le permitieron al capitalismo encadenarse al neoliberalismo y construir un nuevo orden político y social y un nuevo sentido común en torno a sus valores individualistas, liberalizadores e hipermercantilistas. Dicha construcción hegemónica fue posible a partir de una serie de operaciones retórico-políticas. Por un lado, el discurso neoliberal identificó al Estado de Bienestar y al socialismo/ comunismo con el autoritarismo y la ausencia de libertades políticas y civiles para el individuo. Al mismo tiempo, construyó una frontera inversa en defensa de los valores de la democracia, en tanto encadenada a las libertades individuales, en un sentido negativo (en los términos de Berlin, 1993). Por el otro, vinculó al Estado Benefactor y al socialismo/comunismo con un pasado de atraso, decadencia, aislamiento internacional, inflación, ineficiencia, burocratización y déficit fiscal. En contraposición, edificó una cadena significante que identificó al libre mercado con un futuro de estabilidad, crecimiento, libertad de elegir, modernización, progreso e inserción a los beneficios de la globalización, con sus significados adosados de consumo ilimitado, confort, liberación y felicidad plena. Ambas cadenas se acolchonaron en torno al punto nodal libertad y en contra de la intervención opresiva del Estado y sus valores de igualdad social, solidaridad colectiva, participación popular y justicia social (Fair, 2014a). 


\section{La construcción del Amo Neoliberal como una articulación aggiornada del Discurso Capitalista y el Discurso Universitario y una reformulación del Amo antiguo}

Durante los años noventa se estableció un modelo de especulación y valorización financiera del capital, nuevos mecanismos de explotación social de los trabajadores y nuevas pautas de consumo mercantil segmentado que, junto con la acumulación por desposesión de los bienes públicos y comunes, se extendieron a escala mundial. A su vez, intensificaron como nunca antes la lógica de economificación, mercantilización y explotación laboral del sistema capitalista. En ese contexto, el Discurso Amo Neoliberal redefinió las formas de dominación social:

1) En el marco de las políticas de reforma del Estado, el Amo Neoliberal y sus voceros y representantes políticos construyeron y difundieron una lógica capitalista del management que apeló a la necesidad perentoria de flexibilización laboral, como una serie de medidas presuntamente técnicas que suponían la adaptación y adecuación del Esclavo-Trabajador a los nuevos requerimientos del mercado y del mundo moderno. Este discurso proempresarial, inscrito dentro de las ideas de la escuela neoliberal de la elección pública (Public Choice), se articuló con una retórica de modernización, democratización, diálogo, consenso, flexibilidad, horizontalidad y una fantasía de participación del Esclavo en la toma de decisiones en iguales condiciones que el Amo-Empresario. El nuevo régimen de explotación social capitalista se contrapuso al modo de producción fordista, descalificado como burocrático, centralista, vertical, rígido y autoritario.

Desde el análisis de las prácticas discursivas realmente existentes, las políticas de management y de flexibilización del trabajo provocaron un incremento de la precarización laboral, del cuentapropismo, de la diferenciación salarial y de la exclusión social. Además, promovieron una lógica de competencia feroz entre los trabajadores para agradar al Amo-Empresario y una presión de los excluidos del modelo que actuó como ejército de reserva y deprimió los salarios de los Esclavos- 
Trabajadores. Todo ello generó como efecto una creciente fragmentación, heterogeneización, segmentación y polarización de la estructura social. Al mismo tiempo, contribuyó a romper la cohesión social entre los grupos subalternos, debilitó los lazos de solidaridad e identificación social entre los trabajadores y, junto con el temor al despido, redujo la capacidad de organización y acción colectiva de los TrabajadoresEsclavos para enfrentar con éxito al orden neoliberal. En simultáneo con esta fragmentación y debilitamiento del Trabajador-Esclavo, el Amo Capitalista Neoliberal se homogeneizaba de forma creciente y se fortalecía económica, social y políticamente.

2) En el marco de la profundización de la lógica explotadora y mercantilista del Discurso Capitalista, el Amo Neoliberal abandonó la estrategia de universalización de bienes y servicios sociales y de incentivo a la demanda agregada del régimen keynesiano. En su lugar, adoptó una política económica de focalización y ajuste del gasto público y de reducción de los impuestos para los ricos. Para justificar estas políticas favorables al Amo-Empresario, la retórica neoliberal retomó el mito de la "mano invisible del mercado" que se "autorregula" del liberalismo económico smithiano y lo redefinió a partir de la "Teoría del Derrame" ${ }^{\text {"14}}$. Esta teoría fantasiosa asume que el crecimiento económico y la acumulación de riquezas del Amo (grandes empresarios) constituye una condición presunta para luego alcanzar, vía la inversión privada, el "derrame" social de las riquezas hacia el Esclavo (trabajadores). A partir de allí, privilegia políticas ofertistas a favor del Amo Capitalista en desmedro de las políticas de incentivo a la demanda agregada y al consumo interno de los trabajadores del keynesianismo.

3) Al compás de las políticas de privatización y desregulación económica, en esta fase los medios de comunicación se diversificaron, se integraron entre sí y se consolidaron como grupos económicos guiados por el afán de lucro capitalista. De este modo, las empresas

\footnotetext{
14 En el marco de su crítica a La riqueza de las naciones, de Adam Smith, base del liberalismo económico, el propio Lacan sostuvo que "Si le comprás a un rico, a una nación desarrollada, crees — este es el sentido de la riqueza de las naciones— que sencillamente vas a participar del nivel de una nación rica” (Lacan, 2006, p. 87).
} 
multimedios se transformaron en representantes políticos clave del Amo Capitalista Neoliberal. Desde los mass media se incentivó una lógica del show, la primacía de la imagen y la simplificación de los problemas públicos, en desmedro del contenido sustantivo y del predominio de la palabra política que caracterizaban a la etapa anterior. Junto con las estrategias de distorsión de la información y el ocultamiento del sufrimiento social causado por las políticas neoliberales, los medios masivos contribuyeron a reducir la capacidad reflexiva y crítica y a generar una aceptación conformista, resignada y pasiva del orden neoliberal (Bourdieu, 1999). Finalmente, en un contexto de liberalización económica, declive de la imagen paterna y desculpabilización de la riqueza, el Amo Neoliberal logró expandir una nueva lógica capitalista de consumo segmentado de mercancías superfluas, a través de las propagandas desreguladas. Estos objetos-fetiche fueron creados y difundidos como necesidades existenciales para causar su deseo, al vincularse a una fantasía de libertad, satisfacción absoluta y felicidad plena y sin resto para el individuo-consumidor. De este modo, el Amo-Empresario logró sedimentar una ilusoria liberación social del Esclavo-Trabajador. En Argentina, a partir de la fantasía del Plan de Convertibilidad (1991), se exacerbó una lógica de consumo ilimitado de mercancías importadas y de descalificación sistemática de la industria nacional y de las empresas de servicios públicos. Esta lógica, funcional a la dominación del Amo Neoliberal, contribuyó a deslegitimar al Estado Social, a ocultar los sufrimientos sociales provocados por el modelo económico y a generar un imaginario de ascenso social del Esclavo-Trabajador a través del acceso a las prácticas de consumo del patrón. De este modo, el trabajador debilitó sus lazos de solidaridad con los otros trabajadores y tendió a identificarse con el Amo-Empresario.

4) Con el objeto de legitimar ante el Esclavo-Trabajador las políticas económicas favorables al Amo-Empresario, los representantes y voceros del Amo Capitalista Neoliberal fabricaron un relato fantasmático. Por un lado, apelaron a una voz impersonal llamada "el mercado" para exigir la implementación con celeridad de las reformas y ajustes neoliberales, que se asociaron al incremento de la confianza o seguridad jurídica. Junto con el relato de la confianza del mercado (es decir, del 
propio Amo), los exponentes del Discurso Capitalista Neoliberal apelaron a la supuesta ausencia de alternativas a las reformas de mercado. Este discurso mítico, que velaba la alteridad constitutiva que atraviesa lo social, fue acompañado por una tercera estrategia retórica que apelaba a la imposibilidad de modificar el estado de cosas vigente. Todo atisbo de cuestionamiento a los mandatos superyoicos del Dios mercado era vinculado a imaginarios terroríficos de caos (devaluatorio o inflacionario), anomia social y aislamiento del mundo. De este modo, el Amo y sus voceros procuraban generar temor y resignación social frente a todo intento de desobedecer las políticas proempresariales y, así, disciplinar al Esclavo-Trabajador.

5) El Amo Capitalista Neoliberal también incorporó nuevas estrategias retóricas de camuflaje de su dominación ante el Esclavo-Trabajador, que acompañó con políticas públicas de compensación selectiva de los costos del ajuste entre sus principales víctimas. Una de estas estrategias consistió en articular al neoliberalismo con elementos conceptuales que reenviaban a las tradiciones socialistas, laboristas o nacional-populares, de acuerdo a las características de cada cultura política autóctona. De este modo, el Amo Capitalista Neoliberal pretendió velar las formas de explotación social del Esclavo-Trabajador. En Argentina, Menem articuló el neoliberalismo con ciertos significantes de la tradición nacional-popular y de la doctrina peronista, con el objeto de legitimar las políticas proempresariales. En este sentido, sostuvo que la estabilidad económica y las políticas focalizadas eran equivalentes a una mayor "justicia social" para los trabajadores. Además, los Programas de Propiedad Participada en las empresas de servicios privatizadas otorgaban a los trabajadores una "participación" como "socios" en el modelo (Fair, 2014a). De este modo, el Amo-Empresario procuraba generar la ilusión de que el EsclavoTrabajador abandonaba su posición subordinada en la estructura social y pasaba a ser un patrón en iguales condiciones que el Amo.

6) El Amo Neoliberal se articuló con el Discurso Universitario y su presunto saber superior. Contó con el auxilio político de los economistas de las fundaciones ortodoxas, los organismos multilaterales de crédito y otras agencias estrechamente vinculadas con los gru- 
pos empresariales favorecidos por las políticas neoliberales ${ }^{15}$. Estos voceros y representantes del capital concentrado se encargaron de difundir el discurso del Amo Capitalista Neoliberal mediante el fantasma del saber total y la presunta objetividad técnica de las reformas y ajustes promercado. De este modo, se produjo una reformulación del Discurso Universitario sobre la base del sujeto supuesto saber de la ciencia matemática y de las "leyes" de la economía por parte de los economistas ortodoxos, como exponentes de la doctrina "científica" neoliberal. A partir de la ilusión de objetividad de las reformas estructurales y de la supuesta experticie técnica y apolítica para gestionar racionalmente los recursos públicos, el proyecto neoliberal logró asociarse a un mítico discurso técnico, objetivo, científico y de validez universal (Bourdieu, 1999). Esta ligazón mítica contribuyó a naturalizar y a consolidar la dominación política del Amo moderno.

7) A partir de la importancia creciente de los medios masivos de comunicación y del ocultamiento de su estructuración como grupos económicos vinculados a la maximización del lucro capitalista, el Amo Neoliberal estructuró una segunda variante novedosa del Discurso Universitario. Este aggiornamento se apoyó en el presunto saber profesional, apolítico e independiente de lo que piensa la opinión pública o de lo que quiere la gente, a través de la voz de periodistas, editorialistas, encuestadores y otros referentes con visibilidad mediática y prestigio social (escritores, miembros de la Iglesia, etc.). Mediante la apelación al saber de la opinión pública y a la supuesta independencia y objetividad de los periodistas y de otros intelectuales orgánicos con visibilidad pública desde los medios masivos, estos voceros, representantes y colaboradores políticos del Amo contribuyeron a difundir y a naturalizar el relato neoliberal (Harvey, 2007; Vommaro y Rinesi, 2007; Morresi, 2008; Crouch, 2012). De este modo, el proyecto neoliberal incorporó una variante no economicista ni cientificista del Discurso Universitario, que fortaleció la dominación del nuevo Amo ${ }^{16}$.

\footnotetext{
15 Como sostiene Lacan, desde la "función del rico [...] el saber es tan solo un aparato de explotación” (Lacan, 2006, p. 88).

16 Junto con estos voceros y representantes del Amo Neoliberal, debemos destacar también a los representantes de los trabajadores que actuaron como colaboradores del Amo.
} 
8) Finalmente, en los momentos en los que el Discurso Capitalista radicalizado y el Discurso Universitario de los tecnócratas y otros intelectuales orgánicos del modelo eran resistidos por los sectores subalternos, el Amo Neoliberal dejó de lado su relato dialoguista y consensualista y apeló a prácticas de represión física de la protesta social para disciplinar al Esclavo-Trabajador. Contó para ello con el auxilio del Amo antiguo, a través del accionar autoritario de las fuerzas armadas y policiales. Con el objeto de justificar la violencia estatal y la criminalización del derecho a la protesta social, el nuevo Amo y sus voceros construyeron un relato político que culpó al propio Esclavo-Trabajador de su situación de precariedad laboral o desempleo (no trabaja el que no quiere, los que protestan son vagos, hacer una buelga es irresponsable). De este modo, se pretendió desvincular el accionar del Amo-Empresario y la lógica excluyente del Capitalismo Neoliberal de su responsabilidad política en el problema del desempleo, la pobreza y la marginalidad social. Al mismo tiempo, el Amo Neoliberal y sus representantes ignoraron, menospreciaron y/o descalificaron las demandas emancipatorias genuinas y cercenaron los derechos sociales y humanos básicos del Esclavo-Trabajador, en nombre del restablecimiento del orden, la paz y la unidad nacional.

De esta forma, el Amo Neoliberal construyó en los años noventa una nueva modalidad hegemónica de copulación del Discurso Capitalista y el Discurso Universitario que, con el apoyo selectivo del Amo antiguo, le permitió intensificar las formas de dominación política y explotación social del sistema capitalista.

\section{Las fuentes de goce y plus de goce investidas al Discurso Amo Neoliberal}

Desde la teoría lacaniana, todo discurso perdura en el tiempo porque se inviste libidinalmente de goce (Stavrakakis, 2007). Ese goce se instaura a partir de la castración del orden simbólico, por lo que

Entre ellos, una parte del sindicalismo y cuadros intermedios en las empresas privadas que fueron cooptados o colonizados por el discurso hegemónico. 
asume la forma de un goce lenguajero. El goce se materializa a través de objetos metonímicos a causa de deseo, y de metáforas que evocan (con cierta pérdida) la plenitud corporal inalcanzable, lo que Lacan define como el "rasgo unario"(Lacan, 1971-1972; 2003; 2006; 2008), en tanto "deseo del Uno totalizante" (Lebrun, 2003, p. 170). Existe, a su vez, un "plus de goce" que se vincula a un excedente o sobrante de goce y también se estructura desde el orden significante (Lacan, 2006, pp. 18 y ss.). Según Lacan: "Lo importante es que, natural o no, de todas formas, si se puede hablar de goce es como algo vinculado con el origen mismo de la entrada en juego del significante" (Lacan, 2006, p. 191). Por último, el goce posee una dimensión corporal que, si bien se estructura a través del discurso, trasciende a la palabra (por ejemplo, mediante el consumo de drogas que alteran físicamente el organismo) para evocar la unidad corporal perdida (e irrecuperable) de la Cosa (Braunstein, 2006; Rabinovich, 2008). Esto se vincula con la advertencia de Lacan del "discurso como una estructura necesaria que excede con mucho a la palabra". Y con la posibilidad de que exista un "discurso sin palabras", pero cuyas relaciones "no pueden mantenerse sin el lenguaje" (Lacan, 2006, p. 10), lo que el psicoanalista francés ejemplifica con las prácticas gozantes asociadas a la flagelación. Ello implica que las construcciones fantasmáticas se expresan mediante metáforas verbales que remiten a la unidad plena, pero también desde las prácticas sociales de los agentes. Si bien estas adquieren significación a través del orden significante, van más allá del lenguaje, al investirse libidinalmente de un goce que se materializa de forma corporal.

A partir de estas herramientas sostenemos que, en un contexto histórico de derrumbe de la alteridad política que simbolizaba el comunismo, percepción de fracaso de las ideas benefactoras del Estado Social y la creciente sedimentación de los valores liberal-democráticos y mercantilistas:

1) El Discurso Amo Neoliberal se invistió libidinalmente de un goce lenguajero, a través de las construcciones metafóricas de sus representantes, voceros y colaboradores políticos (referentes gubernamentales, periodistas y editorialistas de las empresas multimedios, economistas 
tecnocráticos, grandes empresarios, banqueros, miembros del establishment internacional, consultores, escritores y otros intelectuales orgánicos del modelo). Estos actores de poder difundieron una serie de metáforas que reenviaban a la fantasía del goce unario. Entre ellas, la metáfora del orden internacional como una aldea global, una aldea planetaria o un concierto internacional. De este modo, se velaban las relaciones desiguales de poder y los antagonismos entre los Estados, se eludía lo Real-imposible y se llenaba imaginariamente la falta. También, las metáforas organicistas sobre el sacrificio del trabajador para lograr la sanación del cuerpo social, cuyo plus de goce se derivaba de la necesidad de aplicar las políticas neoliberales.

2) A partir de los mandatos superyoicos difundidos por los representantes gubernamentales y por otros voceros de poder, el Amo Capitalista Neoliberal se invistió de una fuente de goce corporal, producto del acceso fantasmático a una corporeización (discursiva) supuestamente no mediada por el orden simbólico. Este plus de goce se adhirió a las prácticas cotidianas de consumo mercantil de objetos petit a causa de deseo y se encadenó a una fantasía de plenitud y libertad total para los individuos, carente de resto (es decir, a un imaginario de plenitud supuestamente no atravesado por lo Real). La repetición pulsional de estas prácticas mercantilistas, investidas de goce, contribuyó a sedimentarlas y objetivarlas. De esta manera, las mismas se incorporaron como si fueran necesidades naturales no mediadas por la castración fálica.

3) A través del relato de los periodistas, editorialistas y otros referentes políticos de los medios de comunicación concentrados, como supuestos mediadores objetivos e independientes que se limitan a informar, explicar la realidad social y así ayudar al Esclavo (la "gente"), el Amo Capitalista Neoliberal potenció la expropiación plus-gozosa del saber del Esclavo-Trabajador para colocarlo al servicio de la dominación del nuevo patrón.

4) A partir de la fantasía del saber objetivo, neutral y meramente técnico de los economistas ortodoxos, el Amo Capitalista Neoliberal reforzó la reapropiación plus-gozosa del saber popular y del sentido práctico del Esclavo-Trabajador para subordinarlo a los imperativos super- 
yoicos del nuevo Amo. Este giro en el plus de goce se expresó, además, mediante el abandono del circuito de aumentos salariales para fomentar el consumo interno y dinamizar la inversión pública y la producción nacional (con eje en la demanda agregada del trabajador) del modelo benefactor keynesiano. En contraste, el Amo Neoliberal difundió una lógica fiscalista que apelaba a la necesidad del ajuste en los salarios y en los beneficios sociolaborales de los trabajadores. Al mismo tiempo, se debían reducir los impuestos y las regulaciones estatales al accionar de los ricos (con eje en el factor oferta del empresariado), como un modo de generar confianza y seguridad jurídica en el mercado.

5) A través de los mandatos superyoicos de unidad nacional y de pacificación social de los voceros y representantes del patrón, el Amo Capitalista Neoliberal se invistió de goce y justificó las políticas de represión de la protesta social. Las amenazas coercitivas del FMI y los países centrales hacia los países esclavos periféricos fortalecieron la dominación política del Amo a escala internacional.

6) Ahora bien, junto con la reapropiación del goce del Esclavo-Trabajador, el Discurso Neoliberal generó una ilusión de retorno parcial del goce al Esclavo. Mediante el imperativo superyoico de la inserción e integración acrítica a la globalización, el nuevo Amo vehiculizó la ilusión plus-gozosa del reconocimiento existencial por parte de los países más poderosos del sistema mundial hacia los países subdesarrollados. Velando las relaciones desiguales de poder y dominación entre los Estados, en Argentina el goce investido al fantasma del reconocimiento del Amo mundial al país Esclavo justificó la desposesión de los bienes públicos y comunes, la destrucción de la industria nacional, la precarización social del Esclavo-Trabajador y la acumulación de capital del Amo. Este plus de goce del reconocimiento del patrón mundial convertía ilusoriamente a la Argentina en un primus inter pares en América Latina y en motivo de envidia internacional por sus supuestos éxitos económicos y su presunto prestigio.

7) En el marco de las políticas de flexibilización laboral y readecuación administrativa del Estado de acuerdo a criterios manageriales, el Amo 
Capitalista Neoliberal también se mostró cediendo, de forma ilusoria, un plus de goce al Esclavo-Trabajador. Esta transferencia fantasmática de goce se llevó a cabo a través de la difusión de una lógica de las relaciones laborales guiada por prácticas modernizadoras y flexibles, presuntamente más consensuales, participativas y horizontales que los métodos burocráticos, verticales y autoritarios, asociados al modelo taylorista-fordista de posguerra. Finalmente, desde el relato neoliberal las políticas de ajuste luego se traducirían en un derrame espontáneo de las riquezas desde los grandes empresarios hacia los trabajadores, en términos de aumentos salariales, mayor trabajo, progreso y bienestar social. A través de esta fantasía evolucionista, difundida por el Amo Capitalista, las políticas promercado terminarían por favorecer, a la postre, al Esclavo-Trabajador, en lugar de maximizar las ganancias económicas y potenciar la explotación social de los ricos. Estas estrategias retóricas de transferencia ilusoria de goce contribuyeron a velar las relaciones desiguales de poder y los intereses contrapuestos entre el Amo y el Esclavo. Y justificaron la implementación de políticas de ajuste recesivo, explotación laboral y pérdida de los derechos sociales de los trabajadores. Las reformas, además, debilitaron la capacidad de organización y de resistencia política y social del Esclavo-Trabajador para enfrentar al proyecto neoliberal. Al mismo tiempo, acrecentaron la riqueza económica y el poder político del Amo-Empresario capitalista, a través de la reducción de los aportes patronales e indemnizaciones laborales, el incremento del horario y la intensidad del trabajo, el congelamiento y/o la reducción escalonada de los salarios.

\section{El declive de la imagen paterna y el taponamiento imaginario de la falta mediante el Discurso Capitalista Neoliberal}

Las complejas transformaciones promovidas por la ideología neoliberal generaron cambios identitarios que se replicaron en la concepción de la autoridad paterna. Si en la época en la que escribía Freud dominaba una autoridad paternal fuerte y restrictiva, en los noventa se acentuó el declive de la imago paterna, tesis observada tempranamente 
por Lacan. Diversos autores destacaron la crisis del Padre-Amo en la era posmoderna, en estrecha relación con los avances científicos en el campo de la medicina, del papel de la mujer como sujeto pleno de derecho y de las nuevas formas de convivencia sexual. Estas transformaciones promueven una mutación de la familia nuclear y se alejan de la concepción tradicional del Padre-Amo, tal como fuera descrita por Freud a comienzos del siglo pasado (Berdiel Rodríguez, 2009).

Desde una interpretación lacaniana, la crisis de autoridad del PadreAmo no produce una dimisión de la función paterna, sino un cambio de registro. Con el avance del Discurso Capitalista Neoliberal y su articulación a la lógica posmoderna, se efectúa un cambio en la función Nombre del Padre. En los tiempos de Freud el superyó restringía y regulaba el accionar del sujeto a través de una moralidad victoriana que se vinculaba a una sociedad excesivamente disciplinaria. En cambio, el capitalismo neoliberal, a través del Discurso de la Ciencia, fomenta una autoridad sustituta. La nueva fuente de autoridad se basa en una lógica contraria, esto es, en el imperativo superyoico que exige a los sujetos gozar libremente (igoza!) (Žižek, 1992, 2006). El Amo Neoliberal, lejos de impedirle gozar, incita a los sujetos-consumidores a que gocen libremente de los productos mercantiles del Discurso Capitalista sin ningún tipo de límites ni remordimientos éticos o morales. De este modo, antes que una dimisión de la figura del Padre, se produce una declinación de la tradicional imagen del Padre autoritario y castrador. Sin embargo, la función Nombre del Padre retorna en un nuevo registro, de características diferentes.

En el marco de la extensión de un discurso neoliberal contra los autoritarismos y totalitarismos (Estado Benefactor, socialismo, comunismo), la función Nombre del Padre es ocupada por los mandatos superyoicos que incitan al consumo ilimitado de mercancías superfluas. A diferencia del Padre freudiano, que reprimía los instintos y de este modo generaba malestar, en el capitalismo neoliberal la función Nombre del Padre no es restrictiva. Es decir, ya no se encarga de establecer las normas morales prohibitivas (como el incesto), sino que se sitúa como más permisiva, en tanto incentiva a los individuos-Esclavos a gozar libremente (Berdiel Rodríguez, 2009). El nuevo mandato superyoico 
exige disfrutar libremente de un mundo sin límites (Lebrun, 2003). Un mundo en el que la falta constitutiva, la castración simbólica que impide estructuralmente la "relación sexual" (el retorno a la unidad total con el cuerpo de la madre), es forcluida. Así, parece como si nada faltara.

En palabras más simples, el Discurso del Capitalismo Neoliberal incita un cambio en los mandatos del superyó. Estos dejan de ejercer su tradicional papel freudiano de restricción de los instintos para asumir una nueva función liberadora que, imaginariamente, permite (y exige) desear y hacer (cumplir) lo que se desea de forma ilimitada (puedes, por lo tanto, debes, alcanzar la "relación sexual"). El resultado de esta lógica (plus) gozosa es la presencia de un nuevo ordenamiento político y social en el que la tradicional autoridad enunciativa del Padre castrador se desvanece. De este modo, prevalece una sociedad "perversa" en la que fantasmáticamente no existen límites ni restricciones al cumplimiento de los mandatos gozantes de libertad y felicidad absolutas para el individuo, carente de resto ${ }^{17}$. En ausencia de la castración fálica, un relato exacerbado por la televisión comercial y las propagandas desreguladas, los deseos pulsionales parecen ser alcanzados plenamente mediante la lógica mercantilista. Los objetosfetiches del nuevo Amo funcionan, así, como un tapón imaginario para la falta constitutiva del sujeto.

\section{Las mutaciones paradójicas en los mandatos superyoicos del Amo Neoliberal: entre el goce ilusorio del individuo libre y las prácticas castradoras del patrón}

Durante los noventa, al compás de la tesis del Fin de la historia, de Fukuyama, la teoría neoliberal se articuló con la defensa del régimen democrático y las libertades individuales, mientras que en la obra de Friedman y de Hayek ocupaban un lugar subordinado. La retórica

\footnotetext{
17 El término perversión no supone una patología individual, sino que refiere a una estructura discursiva en la que "El deseo no afirma la falta, antes bien, la niega y la niega justo allí donde aparece la prohibición de gozar: en el Otro. El Otro no puede y no debe estar castrado" (Braunstein, 2006, p. 255).
} 
neoliberal tuvo éxito en articular el modelo keynesiano con el autoritarismo y la violencia y en asimilarlo a experiencias dictatoriales y a regímenes totalitarios como el socialismo soviético real. Al mismo tiempo, desde sus políticas individualistas y liberalizadoras, difundió eficazmente un imaginario social de total libertad para los individuos, que fue asociado al fortalecimiento de la democracia (desde una matriz procedimental-liberal). Esta presunta liberación del individuo frente al autoritarismo paternal incluía desde la libertad (formal) para acumular ganancias y consumir todo tipo de mercancías capitalistas en el mercado global, hasta la creciente difusión de libertades para expresarse y asociarse, elegir pareja, casarse y tener relaciones sexuales con quien y cuandoun@ quiera ${ }^{18}$.

Estas transformaciones se condicen con el derrumbe del sistema soviético, el fracaso del Estado keynesiano y el fin de la Guerra Fría. Pese a sus importantes diferencias de forma, de contenido y de grado de intensidad, estas experiencias compartían la existencia de un Estado fuerte. Este tipo de Estado intervenía activamente para regular y ordenar la iniciativa individual a partir de controles y disposiciones estrictas, un sistema de vigilancia centralizada y continua, la exigencia de largos trámites administrativos de cumplimiento obligatorio y un control soberano de las fronteras nacionales y del comercio internacional. En esas circunstancias, el Estado interventor y los funcionarios burocráticos podían ser percibidos como la personificación de un Padre-Amo autoritario, paternalista y controlador.

A partir de estas condiciones, el discurso neoliberal logró sedimentar la articulación entre el Estado interventor (sea cual fuere su orientación ideológica) y la encarnación de un orden social violento, autoritario y patriarcal. Un Estado que, además de ser ineficiente, burocrático y corrupto, oprime a los individuos, cercena las libertades

\footnotetext{
18 Este discurso contra la autoridad castradora paterna y los valores tradicionales, con antecedentes en las luchas de los nuevos movimientos sociales de los sesenta y setenta, se expresa en una creciente aceptación del papel de la mujer y en una mayor aceptación de la diferencia sexual y cultural y de las nuevas identidades sociales. A nivel familiar, el cambio se manifiesta en la creciente relevancia que adquiere el poder materno para ejercer la función paterna, en reemplazo de la arbitrariedad del padre (véase Casas de Pereda, 1994).
} 
individuales y el derecho a la propiedad privada. Al mismo tiempo, la revolución tecnológica y científica, la expansión del fenómeno de la globalización y la competencia entre las grandes empresas privadas permitieron al Amo Neoliberal legitimar su retórica de la "libertad de elegir”, como la denominaba Friedman. Ello promovió una supuesta libertad plena de los individuos para escoger las mercancías deseadas, acumular ganancias de forma ilimitada y desplazarse sin coacciones estatales en el mercado mundial. Las políticas económicas de desregulación y flexibilización laboral del paradigma posfordista y los programas gerenciales, junto con las metáforas unarias del discurso Amo y el ocultamiento de los efectos sociales regresivos de las reformas neoliberales, contribuyeron a fortalecer este relato de liberación social y plenitud. Lo hicieron a partir de una ilusión de eliminación de los controles burocráticos del Estado y de una fantasía de participación democrática, horizontal y dialoguista entre el Esclavo-Trabajador y el patrón.

Sin embargo, al mismo tiempo, observamos en esta etapa un fenómeno paradójico de combinación de una retórica antiestatal, consensualista, democratizadora y liberalizadora, con prácticas fácticas de paternalismo estatal, re-regulación del mercado, autoritarismo político y conservadurismo social. En efecto, la dominación velada del Amo Neoliberal por momentos fue reforzada con un disciplinamiento coercitivo del Esclavo-Trabajador. Ello reenvía a la aplicación de prácticas violentas y autoritarias que contradicen, atributivamente, la prédica de libertad total para los individuos. Así, pese a la aceptación del régimen democrático, el poder paternalista del Amo antiguo no desapareció del discurso neoliberal. En este sentido, durante los noventa el Estado neoliberal no dejó de intervenir activamente para reprimir la protesta social contra los enemigos de la libertad, con el objeto de garantizar el orden público para los grandes capitalistas. De este modo, el nuevo patrón contribuyó a disciplinar al Trabajador-Esclavo. En América Latina, además, el mandato de liberalización económica se contrapuso a una práctica de intervención re-reguladora del Estado al servicio del Amo, que ayudó a conformar o consolidar monopolios y oligopolios no innovadores ni transitorios. El FMI, a su vez, ejerció una dinámica de coacción patriarcal, a través de sus préstamos condicionados a la 
aplicación de las políticas neoliberales en los países periféricos y bajo la amenaza de caos (hiperinflacionario o devaluatorio) y aislamiento internacional, en caso de atreverse a desobedecer sus mandatos. Esta estrategia coercitiva del vocero imperial del Amo convirtió al FMI en el "brazo armado" (Bourdieu, 1999, p. 136) del orden neoliberal, contribuyó a disciplinar a los Trabajadores-Esclavos y garantizó una mayor y mejor explotación social del capital transnacional. También Estados Unidos mantuvo en esta fase una fuerte veta autoritaria, al pretender actuar unilateralmente como patrón del sistema mundial y al apelar a la expansión militarista y neoconservadora para maximizar las ganancias del Amo Capitalista. Finalmente, en particular desde la segunda mitad de los noventa, el neoliberalismo realmente existente se aggiornó y extendió la intervención reguladora del Estado mediante la creación de un marco institucional para las reformas y una serie de políticas compensatorias. Esta malla de reformas de Segunda Generación procuró enfrentar los costos sociales del ajuste y viabilizar el proyecto neoliberal.

De manera tal que observamos una serie de paradojas del Amo neoliberal en el modo de administrar el goce:

1) Por un lado, a través del Discurso Universitario, el Amo Capitalista Neoliberal se apropió del goce del Esclavo-Trabajador. Ello a partir de la mítica idea de objetividad y del saber técnico de la ciencia de los economistas ortodoxos y la presunta profesionalidad y ausencia de intereses políticos particulares de los voceros mediáticos.

2) Al mismo tiempo, el Amo Neoliberal reforzó su dominio político con el auxilio de un discurso autoritario de disciplinamiento social por la vía coactiva. Ello incluyó desde la represión policial de la protesta social, hasta las imposiciones patriarcales del FMI y otros representantes del Amo para disciplinar al Esclavo-Trabajador, generar temor social y provocar angustia frente a la sanción del mercado y la posibilidad de una caída en el infierno del caos.

3) Por otro lado, el Amo Capitalista Neoliberal promovió mandatos superyoicos de consumo de mercancías superfluas que taponaron 
fantasmáticamente la falta constitutiva y liberaron de forma ilusoria al individuo-consumidor de la castración paterna. De este modo, el Amo Neoliberal fomentó cierta capacidad de autonomía a los Esclavos-Trabajadores para decidir por sí mismos entre una multiplicidad de opciones en el mundo del mercado, como un retorno ilusorio del goce al Esclavo ${ }^{19}$.

4) Finamente, el Amo-Empresario neoliberal también se mostró transfiriendo de un modo ilusorio una parte del goce al Esclavo-Trabajador, a través del régimen posfordista de participación descentralizada y de acuerdos dialógicos y horizontales entre empleadores y empleados. De esta manera, generó una fantasía de la toma de decisiones democráticas y compartidas entre el esclavo y el patrón en el nuevo orden flexible, que pretendía contrastar con las formas burocráticas, verticalistas, centralistas y opresivas del modelo fordista-taylorista ${ }^{20}$.

Esta dinámica de dominación social es paradójica ya que, si bien la transferencia ilusoria del goce al Esclavo-Trabajador es funcional a la ideología neoliberal, por otro lado el discurso de la libertad de elegir y de cierta democratización de las decisiones unilaterales también permite cuestionar la autoridad del Amo. De este modo, el discurso Amo genera efectos contradictorios que, de forma no intencional, habilitan a erosionar su legitimidad.

\footnotetext{
19 Una libertad ilusoria para el sujeto, en tanto oculta la esclavitud fáctica a los mandatos del Amo Capitalista, así como la necesidad del Esclavo-Ttabajador de vender su fuerza de trabajo en el mercado para poder subsistir.

20 La participación social que el Amo promueve para los sujetos en tanto consumidores y prosumidores (votaciones telefónicas o por celular, subida de videos de la "gente", intercambio directo de opiniones e imágenes a través de las nuevas redes sociales) podría estar expresando una nueva forma de transferencia ilusoria del goce hacia el Esclavo para reforzar el orden vigente. Se trataría de hacer posible el "deseo de reconocimiento" y de valorar un "saber hacer" en manos del Esclavo, pero no como sujeto colectivo de derecho igualitario, sino como un individuo narcisista que participa de forma virtual y goza de su exhibición pública. Sin embargo, las nuevas tecnologías (Facebook, Twitter) también pueden ser empleadas en una dirección contraria, por lo que no deben ser condenadas a priori.
} 


\section{El Discurso Amo Neoliberal en Argentina: de los mandatos de goce obsceno del menemismo a la austeridad superyoica del delarruismo}

En Argentina, a partir del éxito del Plan de Convertibilidad (1991), el gobierno de Menem promovió una lógica hiperconsumista y ostentosa que exacerbó, desde la cima del poder político, una concepción frívola, exhibicionista y de consumo capitalista ilimitado. A su vez, desde el discurso verbal de Menem, se difundió una prédica de defensa de la democracia y de la libertad política. Sin embargo, esta lógica se contrapuso a sus prácticas autoritarias, iliberales y coercitivas contra los opositores al orden neoliberal (Fair, 2014a).

En octubre de 1999, De la Rúa accedió a la Presidencia a través de un nuevo relato político que, junto con la promesa de preservar el Régimen de Convertibilidad de los noventa ("El modelo no se toca"), promovía un estilo más austero y menos frívolo y exhibicionista. En contraste con la corrupción menemista y su ethos de frivolidad, ostentación, despilfarro de recursos públicos y diversión ilimitada, De la Rúa escenificaba un ethos austero y responsable que fomentaba una gestión honesta y un estilo más sobrio y aburrido (Fair, 2017). Pese a su discurso verbal dialoguista y consensual, durante su gobierno De la Rúa tampoco dudó en apelar a prácticas violentas y autoritarias de represión y criminalización de la protesta social.

En el transcurso de su gestión, De la Rúa mantuvo el Plan de Convertibilidad del menemismo, que se condensaba en el punto de capitón estabilidad. Al igual que en los noventa, la estabilidad en torno al uno a uno ( 1 peso = 1 dólar) continuaba representando un objeto a causa-dedeseo e investido como fuente de goce. Este objeto metonímico causa de deseo se enganchaba a una cadena significante que reenviaba al Discurso Capitalista, a través de la acumulación del capital y el modelo de valorización financiera, y a imaginarios sociales de estabilidad perpetua de los precios, modernización y consumo ilimitado de gadgets importados. Sin embargo, el nuevo gestor del modelo, al mismo tiempo, incorporó un cambio de registro en los mandatos superyoicos. Este giro ideológico se expresó desde un mandato de 
exhibicionismo, frivolidad y consumo obsceno del menemato, a un nuevo mandato de consumo más sobrio, austero y menos ostentoso con la Alianza. El nuevo mandato superyoico de la austeridad convergía con las políticas neoliberales de ajuste ortodoxo y austeridad fiscal que implementó De la Rúa durante su gobierno para preservar la fantasía del uno a uno.

Estas transformaciones político-ideológicas nos permiten distinguir dos subetapas específicas dentro de un mismo proyecto del Amo Capitalista Neoliberal que adquirieron, en Argentina, sus propias particularidades. Mientras que la etapa menemista se caracterizó por la fantasía perversa de liberación total del Esclavo-Trabajador y un modo de goce obsceno, la etapa delarruista significó un retorno parcial del Estado-Amo castrador, desde una matriz superyoica más sobria y austera. De esta manera, la crítica a la "fiesta menemista" implicó un retorno a aspectos más paternalistas y de regulación (selectiva) del Amo Neoliberal. Al mismo tiempo, sin embargo, el menemismo no dejó de apelar al Amo antiguo para disciplinar, de forma coactiva, la protesta social. Y el delarruismo profundizó desde el Estado las políticas neoliberales de desregulación económica y precarización laboral favorables al Amo-Capitalista. De este modo, junto con la preservación del uno a uno como objeto a causa-de-deseo, de Menem a De la Rúa encontramos algunos cambios paradójicos en los mandatos superyoicos y en las formas de administrar el goce.

\section{Reflexiones finales}

Con Lacan sabemos que "no hay relación sexual" y que, por lo tanto, todo discurso está atravesado por la castración fálica y por el registro de lo Real-imposible. En términos de Laclau, no existe una sociedad reconciliada consigo misma, por lo que todo orden social se encuentra estructuralmente dislocado. Desde Lacan "el Real solo puede ser aproximado en conexión con las instancias del Simbólico y del Imaginario con las cuales se anuda para constituir la realidad del sujeto" (Gutiérrez Vera, 2004, p. 323). El orden significante, que anuda borromeicamente estos tres registros (RSI), permite mostrar, 
a través de la simbolización de los síntomas, el carácter precario y fallido ("no todo") de lo social. Ello supone tener en cuenta que "el lenguaje opera su captura de lo real" (Lacan, 2012, p. 32).

A partir de la visibilidad y metabolización significante de los efectos indeseados del experimento neoliberal, en las últimas décadas emergió una serie de síntomas sociales que lograron atravesar la fantasía y poner en evidencia el carácter mítico e ilusorio de la ideología neoliberal. Estos síntomas asumieron diferentes direcciones y grados de estructuración. En el caso argentino, el "Corralito", el default, la devaluación y la pesificación asimétrica de 2002 dislocaron el espacio social, mostraron los efectos reprimidos del Discurso Amo Neoliberal y abrieron la posibilidad de atravesar, de una forma retroactiva, la fantasía ideológica del uno a uno.

Desde una perspectiva lacaniana, se cuestiona al discurso Amo, en todas sus formas y variantes, con el objeto de subvertir su dominación. Las herramientas de la subversión analítica de Lacan, más que las de Freud, permiten criticar y oponerse radicalmente a todas las formas capitalistas, patriarcalistas, universalistas, objetivistas, racionalistas, cientificistas, positivistas y mercantilistas del Amo. En contraste con el discurso Amo y sus variantes solidarias, desde una izquierda lacaniana enfatizamos en la necesidad de construir lazos sociales alternativos que valoren el saber popular y contribuyan a la efectiva emancipación del Esclavo-Trabajador aceptando, al mismo tiempo, que la alteridad es constitutiva y que no existe ningún orden plenamente estructurado. A partir de estas premisas sostenemos que el analista político del discurso debe luchar contra las diferentes formas de opresión y explotación social del Amo (capitalistas, imperialistas, patriarcalistas, racistas, tecnocráticas, burocráticas) y contribuir a la permanente liberación del Esclavo-Trabajador en un marco de reconocimiento del carácter fracturado y fallido (contingente, precario, no todo) de lo social. Ello implica aceptar que la lucha socialista y por las diferentes emancipaciones sociales no puede imponerse desde el dominio de un nuevo líder-Amo que, en el nombre del Pueblo, la Nación o la Clase, y arrogándose el supuesto saber del Esclavo-Trabajador a partir de la ciencia, el progreso, los intereses objetivos o los designios 
de la historia, restrinja o procure eliminar fácticamente la voluntad autónoma y la capacidad decisoria de los grupos subordinados, o refuerce fácticamente las formas de explotación y opresión social sobre los sectores subalternos. Y que la lucha política por la igualdad social se encuentra anudada a una lucha política por la libertad, el reconocimiento y la aceptación de las diferencias, particularidades y singularidades que forman parte de la condición humana e impiden la fantasía ideológica de uniformidad y homogeneidad social.

\section{Referencias}

Alemán, J. (1992). Cuestiones antifilosóficas en Jacques Lacan. Buenos Aires: Atuel. Alemán, J. (2009). Para una irquierda lacaniana. Buenos Aires: Grama.

Álvarez, A. (2006). La teoría de los discursos en Jacques Lacan. Buenos Aires: Letra Viva.

Anderson, P. (1999). Neoliberalismo: un balance provisorio. En E. Sader \& P. Gentilli (Comps.), La trama del neoliberalismo (pp. 25-38). Buenos Aires: EUDEBA. Berdiel Rodríguez, O. (2009). La declinación social de la imago paterna y su correlato simbólico: ¿Sujeto autorreferencial?. Psikeba, (10).

Berlin, I. (1993). Cuatro ensayos sobre la libertad. Madrid: Alianza.

Borón, A. (2000). Tras el búbo de Minerva. Mercado contra democracia en el capitalismo de fin de siglo. Buenos Aires: Fondo de Cultura Económica.

Bourdieu, P. (1999). Contrafuegos. Reflexiones para servir a la resistencia contra la invasión neoliberal. Barcelona: Anagrama.

Braunstein, N. (2006). El goce. Un concepto lacaniano. Buenos Aires: Siglo XXI.

Brenner, N. \& Theodore, N. (2002). Cities and the geographies of actually existing neoliberalism. Antipode, (34), 349-379.

Brown, W. (2006). American nightmare: Neoliberalism, no-conservatism and de-democratization. Political Theory, (34), 690-714.

Casas de Pereda, M. (1994). Función paterna en la familia en este fin de milenio. Revista Uruguaya de Psicoanálisis, (79-80), s/p.

Crouch, C. (2012). La extraña no-muerte del neoliberalismo. Buenos Aires: Capital Intelectual.

De Santos, B. (2006). La fidelidad del olvido. Buenos Aires: El Cielo por Asalto. Dor, J. (1997). Introducción a la lectura de Lacan. Barcelona: Gedisa. 
Dornbusch, R. \& Edwards, S. (1990). Macroeconomía del populismo en América Latina. México: Fondo de Cultura Económica.

Fair, H. (2010). Identidades, discurso y política. La articulación y consolidación de la cadena significante menemista en torno al régimen socioeconómico de la Convertibilidad (1991-1995). Pléyade, (5), 100-176.

Fair, H. (2014a). La readaptación ideológica del orden neoliberal en el discurso menemista. Si Somos Americanos, (14), 103-132.

Fair, H. (2014b). Lo político, la política y las formas de construcción simbólicas e imaginarias del orden social en la teoría de la hegemonía de Ernesto Laclau. Politeia, (53), 169-204.

Fair, H. (2017). La construcción político-discursiva del liderazgo de Fernando De la Rúa en la última etapa de su gobierno. SAAP, (11), 69-102.

Ffrench Davis, R. (2004). Entre el neoliberalismo y el crecimiento con equidad. Buenos Aires: Siglo XXI.

Foucault, M. (2007). Nacimiento de la biopolítica. Buenos Aires: Fondo de Cultura Económica.

Freud, S. (1968). Malestar en la cultura. En Obras completas de Sigmund Frend. Tomo 3. Madrid: Biblioteca Nueva.

Freud, S. (1973). Moisés y la religión monoteísta. En Obras completas de Sigmund Freud. Madrid: Biblioteca Nueva.

García Delgado, D. (1994). Estado \& sociedad. La nueva relación a partir del cambio estructural. Buenos Aires: Norma-FLACSO.

Gill, S. (2015). The geopolitical of global organic crisis. Review of Theory and Culture, (111), 25-36.

Glynos, J. \& Stavrakakis, Y. (2004). Encounters of the real kind. En S. Critchley \& O. Marchart (Comps.), Laclau. A critical reader. London-New York: Routhledge.

Gramsci, A. (1984). Notas sobre Maquiavelo, sobre la política y sobre el Estado moderno. Buenos Aires: Nueva Visión.

Gutiérrez Vera, D. (2004). La textura de lo social. Revista Mexicana de Sociología, (66), 311-343.

Hall, S. (2011). The neo-liberal revolution. Cultural Studies, (25), 705-728.

Harvey, D. (2007). Breve historia del neoliberalismo. Madrid: Akal.

Lacan, J. (1971-1972). El Seminario 19. Ou pire. Buenos Aires: Íntegra.

Lacan, J. (1987). El Seminario 11. Los cuatro conceptos fundamentales del psicoanálisis. Buenos Aires: Paidós.

Lacan, J. (2003). Escritos I. Buenos Aires: Siglo XXI. 
Lacan, J. (2005). El triunfo de la religión. Buenos Aires: Paidós.

Lacan, J. (2006). El Seminario 17. El reverso del psicoanálisis. Buenos Aires: Paidós.

Lacan, J. (2008). El Seminario 20. Aun. Buenos Aires: Paidós.

Lacan, J. (2009). El Seminario 18. De un discurso que no fuera del semblante. Buenos Aires: Paidós.

Lacan, J. (2012). El Seminario 23. El sinthome. Buenos Aires: Paidós.

Laclau, E. (1985). Tesis acerca de la forma hegemónica de la política. En J. Labastida (Coord.), Hegemonía y alternativas politicas en América Latina (pp. 19-44). México: UNAM.

Laclau, E. (1996). ¿Por qué los significantes vacíos son importantes para la política? En E. Laclau. Emancipación y diferencia (pp. 69-86).Buenos Aires: Ariel.

Laclau, E. (2014). Muerte y resurrección de la teoría de la ideología. En Los fundamentos retóricos de la sociedad (pp. 21-50). Buenos Aires: Fondo de Cultura Económica.

Laclau, E. \& Mouffe, C. (2004). Hegemonía y estrategia socialista. Buenos Aires: Fondo de Cultura Económica.

Laurent, E. (1992). Lacan y los discursos. Buenos Aires: Manantial.

Lebrun, J. P. (2003). Un mundo sin límite: Ensayo para una clínica psicoanalítica de lo social. Barcelona: Del Serbal.

Marx, K. (2007). El capital. Crítica de la economía política. Tomo I. México: Fondo de Cultura Económica.

Mazzuca, R. (1992). La segregación y las agrupaciones de analistas.En E. Laurent (Comp.), Lacan y los discursos (pp. 109-115). Buenos Aires: Manantial.

Morresi, S. (2007). ¿Más allá del neoliberalismo? Estado y neoliberalismo en los años noventa. En E. Rinesi, G. Nardacchione \& G. Vommaro (Eds.), Los lentes de Victor Hugo. Transformaciones políticas y desafíos teóricos en la Argentina reciente (pp. 117-150). Buenos Aires: Prometeo-UNGs.

Morresi, S. (2008). La nueva derecha argentina: La democracia sin política. Buenos Aires: UNGs-Biblioteca Nacional.

Peck, J. \& Tickell, A. (2002). Neoliberalizing space. Antipode, (34), 380-404.

Rabinovich, D. (2003. El concepto de objeto en la teoría psicoanalítica. Buenos Aires: Manantial.

Rabinovich, D. (2008). Sexualidady significante. Buenos Aires: Manantial. 
Rinesi, E. \& Vommaro, G. (2007). Notas sobre la democracia, la representación y algunos problemas conexos (pp. 419-472). Buenos Aires: Prometeo-UNGS. Sassen, S. (2007). Una sociología de la globalización. Análisis Político, (26), 61. Schorr, M. (2002). Mitos y realidades del pensamiento neoliberal. En M. Schorr y otros. Más allá del pensamiento único (pp. 11-79). Buenos Aires: CLACSO.

Stavrakakis, Y. (1999). Lacan and the political. London-New York: Routledge. Stavrakakis, Y. (2007). The lacanian left. Psychoanalysis, theory, politics. Edinburgh: Edinburgh University Press.

Thwaites Rey, M. (2003). La (des)ilusión privatista. El experimento neoliberal en la Argentina. Buenos Aires: EudeBA.

Torre, J. C. (1998). Elproceso político de las reformas económicas en América Latina. Buenos Aires: Paidós.

Žižek, S.(1992). El sublime objeto de la ideología. Buenos Aires: Siglo XXI.

Žižek, S. (2005). El objeto a en los lazos sociales. Segunda parte. Recuperado de http://www.imagoagenda.com/articulo.asp?idarticulo $=501$

Žižek, S.(2006). Porque no saben lo que hacen. El goce como un factor político. Buenos Aires: Paidós. 